\title{
Red Cell Distribution Width and Its Relationship with Microalbuminuria Among Patients with Essential Hypertension
}

\author{
Akhshaya Ponsuba $\mathrm{T}^{1}$, Manimaran $\mathrm{D}^{1 *}$, Desigamani $\mathrm{K}^{2}$, Sangeetha $\mathrm{B} \mathrm{S}^{1}$, Rajesh $\mathrm{H}^{1}$ and Sheeja $\mathrm{J}^{1}$ \\ ${ }^{1}$ Department of Pathology Tagore Medical College and Hospital, Rathinamangalam, \\ Melakkottaiyur (PO), Chennai - 600127, Tamilnadu, India \\ ${ }^{2}$ Department of Biochemistry Tagore Medical College and Hospital, Rathinamangalam, \\ Melakkottaiyur (PO), Chennai - 600127 Tamilnadu, India
}

\begin{abstract}
Background: Elevated Red Cell Distribution Width (RDW) is an indicator of renal damage in hypertensive patients. Microalbuminuria (MAU) is an indicator of risk for cardiovascular complications and progressive renal damage in patients with diabetes and also hypertension.

Objectives: 1. Determine RDW and microalbuminuria in hypertensive patients. 2. Determine RDW levels in hypertensive patients with microalbuminuria and without microalbuminuria and to evaluate the relationship between these two parameters.

Methodology: Our prospective study was conducted on 98 patients attending outpatient clinic for blood pressure check up and treatment. For measurement of RDW -2 ml blood was collected by clean venepuncture and collected in EDTA tube and determined RDW by automatic cell counter (sysmex KX-21) and for microalbuminuria - Early morning urine samples were collected and microalbumin determined by immunoturbidimetry. Statistical analysis were done using SPSS version - 16.0.

Results: A total of 98 patients were included in the present study with age ranging from $30-86$ year. All the patients were known hypertensive under treatment and 54 of them also had associated diabetes mellitus. The male to female ratio of the sample was 29:69. Out of the total 98 patients, $58(59.2 \%)$ presented with microalbuminuria and $23(23.5 \%)$ patients had RDW value above normal. Out of the 58 patients with microalbuminuria, 17 (29.3\%) patients had RDW value above normal but only 6 (15\%) patients out of 40 patients without microalbuminuria had RDW value above normal.

Conclusion: Though we could not find out a direct relationship between RDW and MAU, some of the individual patients with MAU had high RDW compared to patients without MAU. As RDW is routinely done as part of complete blood counts in all patients, if its value is high in hypertensive patients, we can workup the patient for microalbuminuria. Early detection and treatment can avoid complications in these patients.
\end{abstract}

Keywords: Essential Hypertension, Microalbuminuria, RDW

\section{Introduction}

Hypertension has become one of the most important public health problem because of the risk of developing chronic kidney disease (CKD) and cardiovascular diseases (CVD).${ }^{[1]}$ Microalbuminuria is abnormal urinary excretion of albumin between 30 and $300 \mathrm{mg} / \mathrm{dl}$ and it is found in 8 to $15 \%$ of hypertensive patients. ${ }^{[2]}$ Patients with microalbuminuria are at risk of developing cardiovascular

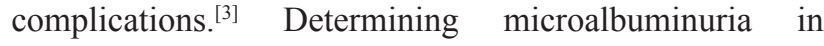
hypertensive patients will help identify patients who are at risk of developing CVD. Red cell distribution width (RDW) is reported as part of complete blood count in hematology laboratory and it is routinely done in all patients. ${ }^{[4]}$ It is a measure of variability in size of erythrocytes and it is useful in evaluation of anemias. Increased RDW is also a predictor of mortality both in general populations and in some selected group of patients like myocardial infarction. ${ }^{[5]}$ High RDW in hypertensive patients is associated with the risk of developing cardiovascular complications. ${ }^{[6]}$ In our study we would like to find out the relationship of RDW with microalbuminuria in hypertensive patients. Only few studies have been done in this area with positive correlation between the two parameters. ${ }^{[4,7]}$ When RDW is elevated we can evaluate the patient for microalbuminuria which is an indicator of renal damage and it will also indicate the increased risk for cardiovascular complications.

\section{Material and Methods}

The study was conducted in a tertiary care hospital in Chennai in the months of April and May 2016 after getting approval from our Institutional Ethical Committee. It is a prospective and cross sectional study conducted on Patients attending medical outpatient clinic for blood pressure check-up and treatment. A total number of 98 patients were included in the study. Patients with essential hypertension aged 18 and above with blood pressure values $\geq 140 \mathrm{~mm}$ 
systolic and $\geq 90 \mathrm{~mm}$ diastolic $(\geq 150 / 90 \mathrm{~mm}$ for patients above 60 years, as per JNC 8) were included in the study. Patients below 18 years of age, hypertension in pregnancy, patients with known secondary hypertension, those with severe anaemia and patients not willing to take part in the study were excluded from the study. Patient details like age, sex, treatment history, comorbidities like diabetes mellitus, obesity, history of myocardial infarction, stroke, renal diseases and other complications were taken.

Venous blood sample and early morning urine sample were collected from all patients after getting informed consent. $2 \mathrm{ml}$ venous blood was collected by clean venepuncture and collected in EDTA tube. RDW was measured by automatic cell counter (sysmex KX-21). Early morning urine sample were collected and microalbumin determined by immunoturbidimetry.

All statistical analysis were done using SPSS software version - 16.0. Spearman's correlation was done between RDW and urine microalbumin. Institutional ethical committee clearance was obtained. Informed consent was obtained from all participants.

\section{Results}

A total of 98 patients were included in the present study with age ranging from $30-86$ year. All the patients were known hypertensive under treatment and 54 of them also had associated diabetes mellitus. The male to female ratio of the sample was 29:69. In our study, urine microalbumin and red cell distribution width (RDW) were analysed.

Out of the total 98 patients, $58(59.2 \%)$ presented with microalbuminuria and $23(23.5 \%)$ patients had RDW value above normal. Out of the 58 patients with microalbuminuria, $17(29.3 \%)$ patients had RDW value above normal but only $6(15 \%)$ patients out of 40 patients without microalbuminuria had RDW value above normal. (Table 1).

Figure 1 show spearman's correlation of urine microalbumin with RDW. Table 2 show $r$ and $p$ values for these parameters. In our study we could not find out any direct correlation between RDW and urine microalbumin. The $r$ and $p$ values were not significant.

Table 1: RDW values in patients with and without urine microalbumin.

\begin{tabular}{|c|c|c|c|}
\hline \multirow{2}{*}{ Urine Microalbumin } & \multicolumn{2}{|c|}{$\begin{array}{c}\text { RDW in fl (standard deviation) } \\
\text { Number of patients }\end{array}$} & Total \\
\cline { 2 - 4 } & $\mathbf{4 6}$ & $\mathbf{7 6}$ & $58[59.2 \%]$ \\
\hline Positive $[\geq 30 \mathrm{mg} / \mathrm{dl}]$ & 41 & $6[29.3 \%]$ & $40[40.8 \%]$ \\
\hline Negative $[<30 \mathrm{mg} / \mathrm{dl}]$ & 34 & $\mathbf{2 3}[\mathbf{2 3 . 5 \%}]$ & $\mathbf{9 8}$ \\
\hline Total & $\mathbf{7 5}$ &
\end{tabular}

Table 2: Show $r$ and $p$ values.

\begin{tabular}{|c|c|c|}
\hline Variable & \multicolumn{2}{|c|}{ Urinary microalbumin } \\
\hline \multirow{2}{*}{ RDW } & r value & 0.164 \\
\cline { 2 - 3 } & p value & 0.113 \\
\hline
\end{tabular}

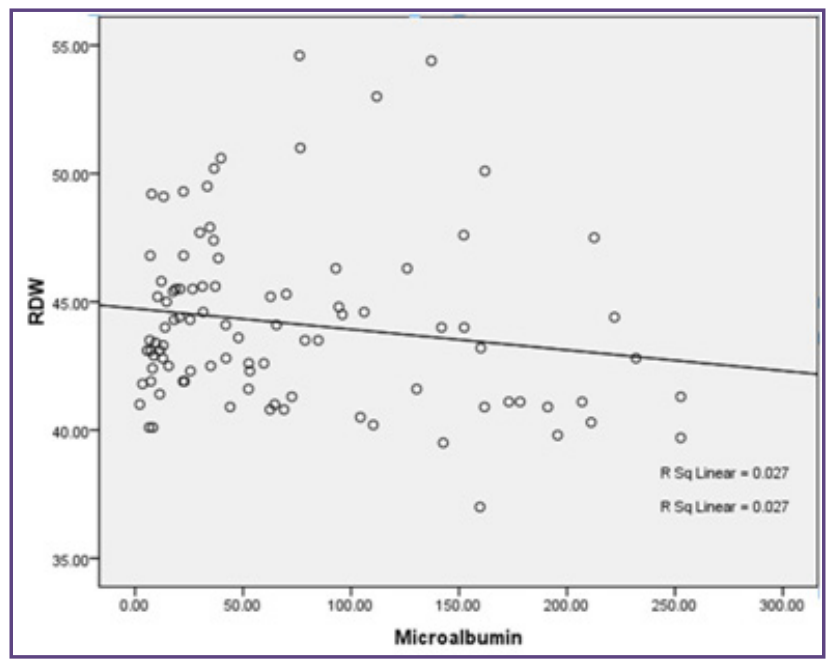

Fig. 1: Spearman's correlation between RDW and urinary microalbumin. 


\section{Discussion}

Microalbuminuria (MAU) occurs in 8 to $15 \%$ of hypertensive patients. ${ }^{[2]}$ In our study, out of 98 patients $58(59.2 \%)$ had MAU. The probable reason for the higher percentage in our study could be, most of our patients were older with long history of hypertension and 54 patients also had associated diabetes mellitus. MAU in hypertension occurs due to hemodynamic changes leading to increased intraglomerular pressure and generalized angiopathy due to endothelial dysfunction. Additional factors include lipid abnormalities, prothrombotic state, oxidative stress and systemic inflammation. Microalbuminuria is an indicator of risk for cardiovascular complications and progressive renal damage in patients with diabetes as well as hypertension. The cardiovascular complication is probably explained by the common pathogenetic mechanism involved in the causation of MAU and atherosclerosis like endothelial dysfunction. ${ }^{[8]}$ Hypertensive patients with microalbuminuria are having more than 4 times the risk of developing ischemic heart disease than hypertensive patients without microalbuminuria. ${ }^{[9]}$ Drug therapy and control of hypertension have beneficial effect of reducing urinary albumin level. ${ }^{[8-10]}$

RDW is measured in laboratories as part of complete blood count and it indicates variability in the size of red blood cells which is called anisocytosis. It is commonly used in the diagnosis of anemias caused by deficiency of iron, vitamin B12 and folic acid. RDW values are also strongly associated with systolic and diastolic blood pressure values. ${ }^{[5,11]}$ Elevated RDW is an indicator of renal damage in untreated hypertensive patients. ${ }^{[6]}$ Wen $\mathrm{Y}$ in his study concluded that RDW is strongly associated with carotid artery atherosclerosis. ${ }^{[7]}$ In a study by Tonelli $\mathrm{M}$ et al ${ }^{[12]}$, they emphasized the relationship between high RDW values with risk of death by cardiovascular events probably due to its association with systemic inflammation. ${ }^{[13]} \mathrm{RDW}$ has also been associated with high sensitivity C-reactive protein (hs-CRP) and erythrocyte sedimentation rate (ESR) in many studies which shows its association with inflammation. ${ }^{[1,13]}$ In our study, RDW values were higher in $23.5 \%$ of patients. We did not attempt to correlate RDW with blood pressure values as all of our patients were already under treatment.

Only few studies were done to find out the relation between RDW and urine microalbumin in patients with essential hypertension. In the study by Afonso L et $\mathrm{al}^{[13]}$, they concluded that there is graded positive relationship between RDW and urine microalbumin independent of other factors like high sensitivity C-reactive protein (hsCRP), comorbidities like hypertension, diabetes and obesity. Both RDW and urine microalbumin are markers of chronic inflammation which explains the positive association. As RDW values were higher even in patients with normal hsCRP levels, they suggested mechanisms other than chronic inflammation like oxidative stresss, endothelial dysfunction and neurohumoral overactivity as the cause. Similar findings were reported in the study by Pusuroglu $\mathrm{H}$ et al. ${ }^{[11]}$ They concluded that increased RDW values are associated with end organ damage (MAU) and inflammation in hypertensive patients.

Jithesh TK et al ${ }^{[14]}$, in their study revealed that though RDW and urine microalbumin increases with various stages of hypertension, they could not establish any correlation between the two pamameters. They have observed that though both RDW and urine microalbumin were elevated in patients with hypertension, elevation in RDW value was not significant. Riju Mathew et al ${ }^{[15]}$, compared urine microalbumin with biochemical and haematological parameters including RDW and found that only ESR and platelet count showed positive correlation with MAU. In our study, though high RDW values were seen in more patients with MAU (29.3\%) compared to patients without MAU (15\%), we could not establish direct correlation between these two parameters.

\section{Conclusion}

Though we could not find out a direct relationship between RDW and MAU, some of the individual patients with MAU had high RDW compared to patients without MAU. As RDW is routinely done as part of complete blood counts in all patients, if its value is high in hypertensive patients, we can work up the patient for microalbuminuria. Early detection MAU and antihypertensive treatment can avoid complications in these patients. Studies with more sample size may be needed for a definitive conclusion.

\section{References}

1. Jithesh TK, Riju Mathew, Jayapal V, Vijayakumar T. Red cell distribution width and high sensitivity C-reactive protein as risk markers in hypertension. Int J Med Sci Public Health 2012;1:138-42.

2. Pontremoli R, Leoncini G, Ravera M, Viazzi F, Vettoretti S, Ratto E, Parodi D, Tomolillo C, Deferrari G. Microalbuminuria, cardiovascular, and renal risk in primary hypertension. J Am Soc Nephrol 2002;13:169-72.

3. Leoncini G, Viazzi F, Parodi D, Ratto E, Vettoretti S, Vaccaro V, Ravera M, Deferrari G, Pontremoli R. Mild renal dysfunction and cardiovascular risk in hypertensive patients. J Am Soc Nephrol 2004;15:88-90.

4. Lippi G, Targher G, Montagnana M, Salvagno GL, Zoppini G, Guidi GC. Relation between red cell distribution width and inflammatory biomarkers in a large cohort of unselected outpatients. Arch Pathol Lab Med 2009;133:628-32. 
5. Tanindi A, Topal FE, Topal F, Celik B. Red cell distribution width in patients with prehypertension and hypertension. Blood Press 2012;21:177-81.

6. Li ZZ, Chen L, Yuan H, Zhou T, Kuang ZM. Relationship between red blood cell distribution width and earlystage renal function damage in patients with essential hypertension. J Hypertens 2014;32:2450-5.

7. Wen Y. High red blood cell distribution width is closely associated with risk of carotid artery atherosclerosis in patients with hypertension. Exp Clin Cardiol 2010;15:37-40.

8. Crippa G. Microalbuminuria in essential hypertension. Journal of Human Hypertension 2002;16:S74-S77.

9. Jenson JS, Feldt-Rasmussen B, Strandgaard S, Schroll M, Borch-Johnsen K. Arterial hypertension, microalbuminuria, and risk of ischemic heart disease. Hypertension 2000;35:898-903.

10. Klausen K, Borch-Johnsen K, Feldt-Rasmussen B, Jensen G, Clausen P, Scharling H et al. Very low levels of microalbuminuria are associated with increased risk of coronary heart disease and death independently of renal function, hypertension, and diabetes. Circulation 2004; $110: 32-5$.
11. Pusuroglu H, Akgul O, ERturk M, Surgit O, Tasbulak O, Akkaya E, et al. Red cell distribution width and end organ damage in patients with systo-diastolic hypertension. Arch Med Sci 2016;12:319-25.

12. Tonelli M, Sacks F, Arnold M, Moye L, Davis B, Pfeffer M. Relation between red cell distribution width and cardiovascular event rate in people with coronary disease. Circulation 2008;117:163-8.

13. Afonso L, Zalawadiya SK, Veeranna V, Panaich SS, Niraj A, Jacob S. Relationship between red cell distribution width and microalbuminuria: a population-based study of multiethnic representative US adults. Nephron Clin Pract 2011;119:277-82.

14. Tharayil Kattil Jithesh, Riju Mathew, Vidyadharan Jayapal, Thankappan Vijajakumar. Microalbuminuria and red cell distribution width as predictive markers of renal involvement in hypertension. Int J Health Rehabil sci 2012;1:99-106.

15. Mathew R, Pai VR, Vijayakumar T. Comparison of microalbuminuria with biochemical and haematological parameters as a marker for renal involvement in patients at high risk for chronic kidney disease - A pilot study. International Journal of Science and Engineering research 2014;5:97-100.

*Corresponding author:

Dr. Manimaran.D, No 5, LIC Colony Main Road, Velachery, Chennai - 600042., Tamil Nadu, India.

Phone: +91 9841310232

Email: manimaranpath@tagoremch.com

Financial or other Competing Interests: None. 